\title{
The trend of caesarean delivery in the Islamic Republic of Iran
}

\author{
F. Bahadori, 'S. Hakimi ${ }^{2}$ M. Heidarzade ${ }^{3}$
}

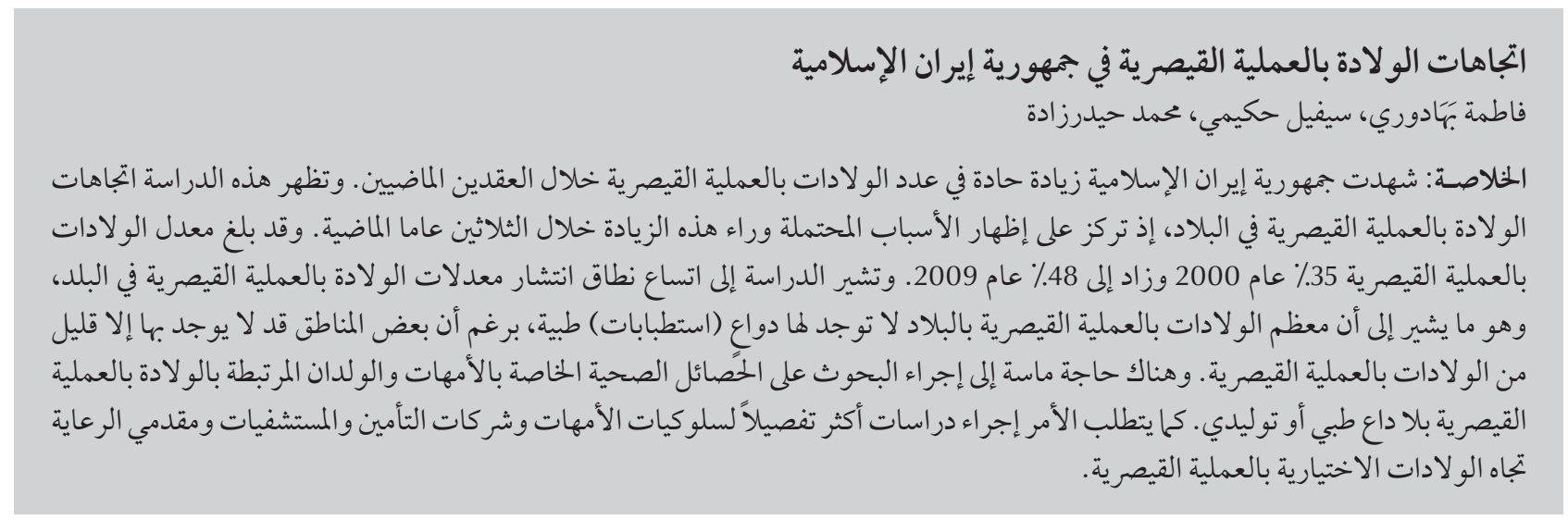

ABSTRACT The Islamic Republic of Iran has witnessed a sharp increase in the number of caesarean sections in the past two decades. This study shows the trend of caesarean sections in the country, focusing on the probable causes of the increase during the past 30 years. The caesarean section rate was 35\% in 2000 and increased to $48 \%$ in 2009 . The study shows that there is a very wide range of prevalence of caesarean section rates in the country. This would indicate that most caesarean sections in our country are not medically indicated, although perhaps in some areas there are not enough caesarean sections. There is a need for research on health outcomes for mothers and infants associated with caesarean delivery without a medical or obstetrical indication. A more detailed examination is needed of mother, insurer, hospital and provider attitudes toward elective caesareans.

\section{Évolution des accouchements par césarienne en République islamique d'Iran}

RÉSUMÉ En République islamique d'Iran, le nombre de césariennes a connu une forte augmentation ces vingt dernières années. La présente étude montre l'évolution des césariennes dans le pays et s'intéresse notamment aux causes probables de cette hausse depuis trente ans. Le taux de césarienne était de $35 \%$ en 2000 . II a atteint $48 \%$ en 2009. L'étude montre que la prévalence des taux de césarienne est très variable dans le pays. Ces éléments suggèrent que la plupart des césariennes pratiquées dans notre pays ne sont pas médicalement indiquées, bien que le nombre de césariennes dans certaines régions soit peut-être insuffisant. II faut mener des recherches sur les résultats pour la santé des mères ayant accouché par césarienne et des nourrissons nés par césarienne en l'absence de justifications médicales ou obstétricales. Il convient d'examiner plus en détail les attitudes des mères, des assureurs, des hôpitaux et des dispensateurs de soins en ce qui concerne la césarienne élective. 


\section{Introduction}

Caesarean section is one of the commonly performed surgical procedures in obstetrics and is certainly one of the oldest operations in surgery [1]. Caesarean section deliveries are typically performed in the presence of medical indicators which render vaginal delivery potentially harmful to the mother or baby [2]. The World Health Organization (WHO) puts the acceptable rate of caesarean section at between $10 \%$ and $15 \%$ of all births in developed countries [3]. However the rate has been increasing worldwide, and this is a growing concern in many countries. Once limited to Western countries, particularly the United States and United Kingdom, high rates of caesarean deliveries are now an international phenomenon, reflecting, in part, increased hospitalbased delivery and access to healthcare. The rise of caesarean births has been the subject of continuing debate [4]. In the Islamic Republic of Iran, the past 2 decades have witnessed a sharp increase in the number of caesarean section operations [5]. This study shows trends of caesarean section in the Islamic Republic of Iran in recent years, focusing on probable causes of the increase.

\section{Methods}

The national caesarean section rate was obtained from several data sources:
- caesarean section rates from routine data gathering systems from government health offices

- caesarean section rates reported in national surveys including the integrated monitoring and evaluation system

- caesarean section rates retrieved from the WHO database

- caesarean section rates published in the literature

\section{Results}

Caesarean section rates by province are shown in Table 1. Figure 1 illustrates the trend of caesarean sections from 2000 till 2009. In 2005 an integrated

\begin{tabular}{|c|c|c|c|c|}
\hline Location & $2005(\%)$ & $2007(\%)$ & $2009(\%)$ & Percentage point change \\
\hline Islamic Republic of Iran & 38.4 & 45.0 & 47.9 & +9.5 \\
\hline Gilan & 64.3 & 70.0 & 73.4 & +9.1 \\
\hline Mazandaran & 46.3 & 61.5 & 63.7 & +17.3 \\
\hline Tehran & 53.5 & 60.0 & 74.3 & +20.8 \\
\hline East Azerbaijan & 42.2 & 54.0 & 62.1 & +19.9 \\
\hline Isfahan & 49.5 & 53.5 & 56.8 & +8.1 \\
\hline Ardebil & 43.1 & 52.0 & 52.7 & +9.8 \\
\hline Qom & 48.1 & 52.0 & 53.1 & +5.2 \\
\hline Ghazvin & 43.6 & 52.0 & 57.1 & +13.5 \\
\hline Semnan & 50.3 & 50.5 & 54.1 & +4.3 \\
\hline Ilam & 50.1 & 49.0 & 47.4 & -2.7 \\
\hline Yazd & 44.4 & 48.0 & 44.7 & +0.3 \\
\hline Kermanshah & 38.2 & 46.0 & 47.4 & +9.2 \\
\hline Kerman & 38.7 & 45.5 & 49.2 & +10.5 \\
\hline Markazi & 42.8 & 44.0 & 61.3 & +18.5 \\
\hline Fars & 31.2 & 43.3 & 41.3 & +10.1 \\
\hline Golestan & 38.6 & 43 & 55.3 & +16.7 \\
\hline Chahar Mahaal & 42.6 & 42 & 39.3 & -3.3 \\
\hline Khuzestan & 35.8 & 42 & 51.3 & +15.5 \\
\hline Hamedan & 32.2 & 40 & 44.3 & +12.1 \\
\hline Khorasan Razavi & 46.9 & 38.3 & 48.4 & +1.5 \\
\hline Lorestan & 36.1 & 39 & 49.6 & +13.5 \\
\hline Bushehr & 57.3 & 36 & 31.7 & -25.6 \\
\hline West Azerbaijan & 29.2 & 34 & 33.6 & +4.4 \\
\hline Kohgiluyeh & 22.5 & 34 & 42.6 & +20.1 \\
\hline North Khorasan & 23.4 & 33 & 34.0 & +10.6 \\
\hline Kordestan & 27.2 & 33 & 35.1 & +7.9 \\
\hline South Khorasan & 25.2 & 32 & 38.2 & +13 \\
\hline Hormozgan & 23.9 & 31 & 56.7 & +32.8 \\
\hline Zanjan & 28.4 & 25 & 33.1 & +4.7 \\
\hline Sistan & 9.1 & 23 & 22.4 & +14.3 \\
\hline
\end{tabular}




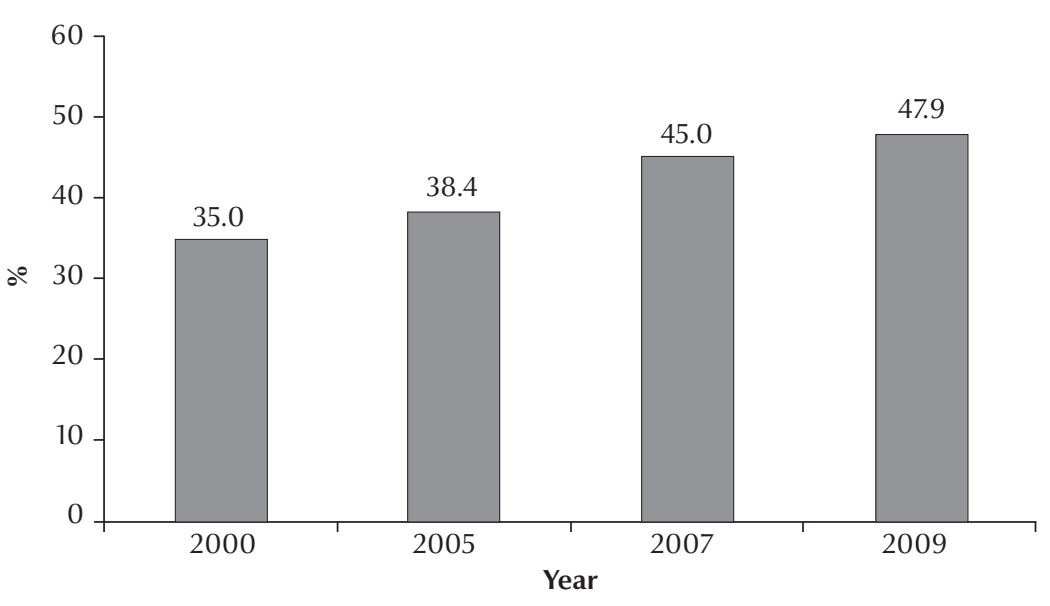

Figure 1 Trend in caesarean section rate, Islamic Republic of Iran, 2000-2009 (Source: [23])

monitoring and evaluation system survey was conducted throughout the country, and the caesarean section trend was estimated at $40.4 \%$. The caesarean section rate in 2005 in private and public hospitals was $64.3 \%$ and $36.4 \%$ respectively. The caesarean section rate in urban areas in 2005 was $46.7 \%$ and in rural areas was $27.6 \%$.

\section{Discussion}

The result of this research showed that the prevalence of caesarean section in Islamic Republic of Iran is very high. In both urban and rural areas the figures were much greater than the ceiling (15\%) recommended by WHO [6]. It is argued that over the past 25 years there has been a sustained rise in caesarean section rates around the world, both in developed and developing countries [7-9]. Rutkow reported that caesarean section delivery accounted for $21 \%$ of all live births in the United States in 1984; this rate increased up to $24.4 \%$ in 2001 as reported by Martin et al. and reached $30.3 \%$ in 2008 . In 1980, the rate in the UK was $9 \%$, increasing to $21.3 \%$ in 2000 and $22 \%$ in $2008[3,10]$. The percentage of caesarean sections in Islamic Republic of Iran has increased sharply in recent years. A study of over 600000 births that took place in a public hospital in
Tehran found a mean caesarean section rate of $3.1 \%$ for the 15 -year period 1967-1983 [11]. The caesarean section rate was 35\% in 2000 and reached 47.9 in 2009 [12,13]. The caesarean section rates in Islamic Republic of Iran seem to be as high as those reported from Brazil (41.3\%) and China (40.5\%) [3] and not comparable with caesarean section rates in other Eastern Mediterranean Region countries. The caesarean section rate varies from 9.3\% in Morocco to $27 \%$ in Egypt $[14,15]$. Data gathered from hospital information systems showed the caesarean section rate to be $38.4 \%$ in 2005 , yet caesarean section prevalence extracted from the integrated monitoring and evaluation system survey was $40.4 \%$ in 2005 . Overall, it seems that two percentage points of error is acceptable for a national survey, and misreports/underreports in mode of birth are not significant. The prevalence of caesarean sections in urban areas is significantly higher to that in rural areas. Our findings are in line with Kukura's research [16]. Maybe women who live in rural areas have fewer delivery mode options and limited financial resources.

The caesarean section rate in private hospitals is nearly twice that of public hospitals because government-run hospitals do not allow elective caesarean sections, and caesarean section without medical indication is not on the insurance list. All hospitals with rates of caesarean section higher than $70 \%$ were in the private sector. The provinces plus Tehran city differed markedly in terms of caesarean section rates (Table 1). The rate of caesarean section in Tehran is higher than 70\% and in Sistan province is less than $30 \%$. The prevalence of caesarean section is significantly higher in developed provinces. Unfortunately we could not report how many caesarean sections were elective because patient choice is not documented in medical records. We found in this research evidence that shows the large proportion of caesarean section cases in our country are not medical indicated, and meaningful differences in rates between provinces and between rural and urban areas confirm the hypothesis of unnecessary caesarean sections in the Iranian health system.

There are several factors that may have contributed to the increase in caesarean deliveries. Discussions of the reasons for the growth in caesareans have centred on changing attitudes concerning caesareans among physicians and mothers $[17,18]$. Leitch and Walker concluded that indications for caesarean did not change much over time [19] and nonmedical factors affect caesarean section prevalence. Similar to other studies in developing countries such as Brazil, Mexico and Thailand, nonmedical factors were found to be more important than medical ones in the decision to deliver by caesarean section [20]. One major reason for this increase is the increased perception among women of these procedures as safe, despite the associated risks and increased costs. Lack of confidence, fear of pain and the experience of previous negative birth outcomes leads women to select caesarean section $[2,21]$. Maternal age rising at the time of first delivery is another reason for increasing numbers of caesarean sections [22]. Yazdizadeh and colleagues in their qualitative study, in which participants were selected from all of country, found that 
many obstetricians prefer caesarean sections because of fear of litigation. Economic issues were considered as one of the most important barriers faced by specialists. Many of the specialists believed the lower tariff set for specialists in charge of vaginal delivery increased their tendency towards performing caesarean sections. Some of them also claimed that the fee paid for vaginal delivery is not worth the time consumed and stress endured during such a procedure [23]. One the other hand there is an increased the tendency towards using caesarean sections in self-governing hospitals where user fees and insurance payments are the main sources of income. The cost of caesarean section in government-run hospitals is approximately $1.5-2$ times as much as that of vaginal delivery [24].

Obstetricians have long believed that caesarean delivery substantially increases the risk of maternal death, and there are extensive data to support that belief; the risk of death with caesarean delivery has been estimated to be several times that associated with vaginal delivery. Operative complications including infection, haemorrhage and visceral injury are important considerations. Infections have been noted to occur in up to $10 \%$ of patients after caesarean delivery, even when prophylactic antibiotics are used, although rates are lower among women who have caesarean deliveries that are not preceded by labour or the rupture of membranes [24]. Repeat caesarean deliveries are associated with significantly higher maternal and neonatal morbidity and mortality compared with caesarean or vaginal deliveries for women who have not had a prior caesarean [17].

There is a clear need for research on health outcomes for mothers and infants associated with caesarean delivery without a medical or obstetrical indication. A more detailed examination is needed of mother, insurer, hospital and provider attitudes toward elective caesareans. More studies, both quantitative and qualitative, of how mothers and clinicians view the birth process and the interaction between mothers and providers could assist in resolving some of these issues. Research on the economic implications of the rising caesarean rate for hospitals, providers, insurers and parents is also essential.

\section{References}

1. Geidam $A D$ et al. Rising trend and indications of caesarean section at the university of Maiduguri teaching hospital, Nigeria. Annals of African Medicine, 2009, 8:127-132.

2. Moscariello M, Bol K. Cesarean section deliveries and inductions of labor in Colorado: an analysis of current trends and demographics. Denver, Colorado Department of Public Health and Environment, 2011. Health Watch 81.

3. Gibbons L et al. The global numbers and costs of additionally needed and unnecessary caesarean sections performed per year: overuse as a barrier to universal coverage. Geneva, World Health Organization, 2010 (World Health Report (2010) background paper 30).

4. Joesch JM, Gossman GL, Tanfer K. Primary cesarean deliveries prior to labor in the United States,1979-2004. Maternal and Child Health Journal, 2008,12:323-331.

5. Ahmad-Nia $\mathrm{S}$ et al.Caesarean section in the Islamic Republic of Iran: prevalence and some sociodemographic correlates. Eastern Mediterranean Health Journal, 2009, 15:1389-1398.

6. Appropriate technology for birth. Lancet, 1985, 2:436-437.

7. Wagan F, Memon GN. Changing trends of indications and rate of cesarean section: an audit. Medical Channel, 2011, 17:63-67.

8. Back C, Kaye J, Jick H. Cesarean delivery in the United Kingdom, time trends in the general practice research database. Obstetrics and Gynecology, 2005, 160:151-155.

9. Lumbiganon P et al. World Health Organization Global Survey on Maternal and Perinatal Health Research Group. Method of delivery and pregnancy outcomes in Asia: the WHO global survey on maternal and perinatal health 2007-08. Lancet, 2010, 375:490-499.

10. Royal College of Obstetricians and Gynaecologists. The national sentinel caesarean section audit report. London, RCOG Press, 2001.

11. Farhud DD, Kamali MS, Marzban M. Annuality of birth, delivery types and sex ratio in Tehran, Iran. Anthropologischer Anzeiger, 1986, 44:137-141.
12. Demographic health survey (DHS). Tehran, Ministry of Health and Medical Education, 2010.

13. Khani S, Shabakhani B. [Can the caesarean rate be reduced in Mazandaran?]. Journal of Mazandaran University of Medical Sciences, 2004, 45:43-50 [in Farsi].

14. Khawaja M, Choueiry N, Jurdi R. Hospital-based caesarean section in the Arab region: an overview. Eastern Mediterranean Health Journal, 2009, 15:458-469.

15. Jurdi R, Khawaja M. Caesarean section rates in the Arab region: a cross-national study. Health Policy and Planning, 2004, 19(2):101-110.

16. Kukura E. Choice in birth: preserving access to VBAC. Penn State Law Review, 2010, 114(3):955-1001.

17. MacDorman MF, Menacker F, Declercq E. Cesarean birth in the United States: epidemiology, trends, and outcomes. Clinics in Perinatology, 2008, 35:293-307.

18. Hale RW, Harer WB. Elective prophylactic cesarean delivery [Editorial]. ACOG Clinical Review, 2005, 10(2):1 and 15.

19. Leitch $C R$, Walker JJ. The rise in caesarean section rate: the same indications but a lower threshold. British Journal of $\mathrm{Ob}$ stetrics and Gynaecology, 1998, 105:621-626.

20. Mossialos E et al. An investigation of Caesarean sections in three Greek hospitals: the impact of financial incentives and convenience. European Journal of Public Health, 2005, 15:288-295.

21. Alehagen S, Wijma K, Wijma B. Fear during labor. Acta Obstetricia et Gynecologica Scandinavica, 2001, 80:315-320.

22. RoudiFahimi F. Iran's family planning program: responding to a nation's needs. Tehran, Population Reference Bureau, 2002.

23. Yazdizadeh $B$ et al. Cesarean section rate in Iran, multidimensional approaches for behavioral change of providers: a qualitative study.BMC Health Services Research, 2011, 11:159.

24. [Guidelines for calculation of caesarean section and vaginal delivery price]. Tehran, Ministry of Health and Medical Education, 2011 [in Farsi]. 